\title{
Erratum to: Plant Fidelity in Somatic Embryogenesis-Regenerated Plants
}

\author{
Hervé Etienne, Romain Guyot, Thierry Beulé, \\ Jean-Christophe Breitler and Estelle Jaligot
}

\section{Erratum to:}

Chapter 8 in: V.M. Loyola-Vargas

and N. Ochoa-Alejo (eds.), Somatic Embryogenesis:

Fundamental Aspects and Applications, DOI 10.1007/978-3-319-33705-0_8

The book was inadvertently published with an incorrect tagging of given names and family names in the affiliation part of Chap. 8: The author names should be displayed as H. Etienne, R. Guyot, T. Beulé, J.-C. Breitler, E. Jaligot. The chapter and the book have been corrected.

The updated original online version for this chapter can be found at DOI 10.1007/978-3-319-33705-0_8

H. Etienne $(\bowtie) \cdot$ J.-C. Breitler

CIRAD, UMR IPME, 911 Avenue Agropolis, BP 64501, 34394 Montpellier, France

e-mail: herve.etienne@cirad.fr

R. Guyot

IRD, UMR IPME, 911 Avenue Agropolis, BP 64501, 34394 Montpellier, France

T. Beulé · E. Jaligot

CIRAD, UMR DIADE, 911 Avenue Agropolis, BP 64501, 34394 Montpellier, France 